\title{
The impact of sampling and measurement on the prevalence of self-reported pain in Canada
}

\author{
Elizabeth G Van Den Kerkhof RN MSc DrPH ${ }^{1,2}$, Wilma M Hopman MA ${ }^{2,3}$, Tanveer E Towheed MD MSc FRCPC 2,4 , \\ Tassos P Anastassiades MD PhD FRCPC ${ }^{4,5}$, David H Goldstein MB BcH MSc FRCPC ${ }^{1,6}$, \\ the Canadian Multicentre Osteoporosis Study Research Group ${ }^{7}$
}

EG Van Den Kerkhof, WM Hopman, TE Towheed, TP Anastassiades, DH Goldstein. The impact of sampling and measurement on the prevalence of self-reported pain in Canada. Pain Res Manage 2003;8(3):157-163.

BACKGROUND: Pain is an important public health problem in Canada. International estimates of general population pain prevalence range from $2 \%$ to $46 \%$.

OBJECTIVES: The purpose of this paper is to critically examine the potentially misleading use of overall prevalence estimates in the pain literature and to use two Canadian population-based surveys to assess the impact of sampling and measurement on prevalence.

METHODS: Two of the secondary data sets used were the 1996/97 National Population and Health Survey (NPHS) and the Canadian Multicentre Osteoporosis Study (CaMos). This paper is based on the assessment of chronic pain in the NPHS, and the assessment of short term pain using the Medical Outcomes Trust's 36-item health survey and the Health Utilities Index, both collected by CaMos. Data are presented as frequencies and percentages overall and stratified by age and sex. CaMos prevalence estimates were age- and sex-standardized to the NPHS population.

RESULTS: The overall prevalence of pain was 39\% for one-week pain, $66 \%$ for four-week pain and $15 \%$ for chronic pain. Women were more likely to report pain than men and the prevalence of pain increased with age.

CONCLUSIONS: This study yields useful information about the self-reported responses to a variety of questions assessing pain in the general population. Responses to the different questions likely represent different categories of pain, such as short term versus chronic pain, which in turn may have different epidemiological risk factors and profiles. Longitudinal studies of the epidemiology, predictors and natural history of chronic pain are urgently needed in the Canadian population.

Key Words: Bias; Canada; Chronic pain; Health utilities index; Measurement; National Population and Health Survey; Pain; Sampling; Secondary data; Self-report, SF-36

\section{L'influence de l'échantillonnage et des mesures sur la prévalence de la douleur auto-évaluée au Canada}

CONTEXTE : La douleur constitue un important problème de santé publique au Canada. Selon différentes évaluations internationales, la prévalence de la douleur dans la population en général varie de 2 à $46 \%$. OBJECTIFS : Le présent article propose un examen critique de l'utilisation potentiellement trompeuse des évaluations de la prévalence générale de la douleur dans la documentation sur le sujet et, pour ce faire, les auteurs ont eu recours à deux études fondées sur la population au Canada pour évaluer l'influence de l'échantillonnage et des mesures sur la prévalence.

MÉTHODE : Nous avons utilisé deux ensembles de données secondaires, soit ceux de l'Enquête nationale sur la santé de la population 1996-1997 et de l'étude Canadian Multicentre Osteoporosis Study (CaMos). L'article repose sur l'évaluation de la douleur chronique dans le cas de l'Enquête nationale et sur celle de la douleur aiguë et subaiguë à partir du Medical Outcomes Trust, enquête sur la santé en 36 points, et de l'Health Utilities Index dans le cas de la CaMos. Les données sont présentées sous forme de fréquences et de pourcentages généraux ou stratifiés selon l'âge et le sexe. Les évaluations de la prévalence dans l'étude CaMos ont été normalisées selon l'âge et le sexe en fonction de la population à l'étude dans l'Enquête nationale.

RÉSULTATS : La prévalence générale de la douleur s'est établie à $39 \%$ pour la douleur aiguë (1 semaine), à $66 \%$ pour la douleur subaiguë (4 semaines) et à $15 \%$ pour la douleur chronique. Les femmes signalaient plus facilement que les hommes la présence de douleur et la prévalence de la douleur augmentait avec l'âge.

CONCLUSIONS : La présente étude livre de l'information utile sur les réponses fournies par les personnes à différentes questions sur l'évaluation de la douleur dans la population en général. Les réponses font probablement référence à différents types de douleur, par exemple aiguë, subaiguë ou chronique, qui à leur tour peuvent être liés à des tableaux et à des facteurs de risque épidémiologiques différents. Le besoin d'études longitudinales sur l'épidémiologie, les prédicteurs et l'évolution naturelle de la douleur chronique au sein de la population canadienne se fait de plus en plus pressant.
Pain is an important and common public health problem in Canada. Results from the 1994/95 National Population and Health Survey (NPHS) indicated that $17 \%$ of the Canadian population has chronic pain (1). Chronic pain adversely affects quality of life and employment status, and is also associated with increased health care utilization. The epi- demiology of pain is not well understood. Chronic pain is defined in the literature as pain lasting for two weeks or longer. Estimates of chronic pain in the general population range from $2 \%$ to $46 \%$ (2). Even less is known about the prevalence of 'short term' pain. The heterogeneity of pain prevalence estimates is most likely due to a lack of a consistent definition for

${ }^{1}$ Department of Anesthesiology, Queen's University; ${ }^{2}$ Deparment of Community Health and Epidemiology, Queen's University; ${ }^{3}$ Clinical Research Unit, Kingston General Hospital; ${ }^{4}$ Deparment of Medicine (Rheumatology), Queen's University; ${ }^{5}$ Deparment of Medicine (Biochemistry), Queen's University; ${ }^{6}$ Deparment of Surgery, Queen's University, Kinston, Ontario; 7 list appears at the end of the article

Correspondence: Dr Elizabeth G Van Den Kerkhof, Deparment of Anesthesiology, Queen's University, Kingston General Hospital,

76 Stuart Street, Kingston, Ontario K7L 2V7. Telephone 613-549-6666x3964, fax 613-548-1375, e-mail ev5@post.queensu.ca 
chronic pain, the wording of specific questions and a lack of representativeness in studies whose results are being generalized to the general population.

The purpose of this paper is to critically examine the potentially misleading use of overall prevalence estimates in the pain literature and to use two Canadian population-based crosssectional surveys to illustrate the impact of measurement (pain duration and questions asked) and sampling (eg, age and sex of the respondents) on prevalence estimates. To determine trends in the reporting of chronic pain in Canada, data from the 1996/97 NPHS were compared to data obtained from the 1994/95 NPHS.

\section{METHODS AND MATERIALS}

Two secondary data sets were used for this analysis the 1996 NPHS and the Canadian Multicentre Osteoporosis Study (CaMos) $(3,4)$. The NPHS was conducted by Statistics Canada and was designed to collect information related to the health of the Canadian population. The survey has a crosssectional and a longitudinal component. The 1996/97 cross-sectional survey consisted of 210,377 general interviews and 81,804 in-depth interviews. The overall response rate at the household level was $82.6 \%$. The 1996/97 longitudinal sample consisted of 16,168 respondents with an overall response rate of $93.6 \%$. Additional details about the NPHS are available elsewhere (5). The data were weighted to reflect the sample design and the adjustments for nonresponse, and post-stratification (3) and estimates were calculated to represent the total Canadian population. The NPHS is based on randomly selected noninstitutional respondents of Canadian households. This paper includes NPHS respondents age 25 years and older who were interviewed in the 1996/97 cross-sectional study.

The CaMos is a prospective cohort study involving 9423 randomly selected Canadian men and women aged 25 years or older and living in the community. The sample was drawn from a $50 \mathrm{~km}$ radius of nine Canadian cities, including St John's, Newfoundland; Halifax, Nova Scotia; Quebec City, Quebec; Kingston, Toronto and Hamilton, Ontario; Saskatoon, Saskatchewan; Calgary, Alberta; and Vancouver, British Columbia. Households were randomly selected from telephone directories, mailed a letter of introduction, and subsequently telephoned to assess their interest in participation. If more than one eligible person resided in the home, a random number table was used to select the participant. Of the 80,163 households sampled, $59.0 \%$ were ineligible because the age, sex or calendar period stratum had already been filled. Another $7.8 \%$ were invalid numbers, and $5.2 \%$ were unreachable after 12 attempts. Of the remaining households, $28.4 \%$ declined to participate, $29.6 \%$ completed a short questionnaire that provided information about the age, sex distribution and fracture history of the residents, and 9423 (42.0\%) went on to participate fully in the study. Additional details about the CaMos study are available elsewhere $(4,6)$. Ethical approval for the study was obtained through the review boards of each participating centre, as well as through the coordinating centre in Montreal.

CaMos is designed to collect epidemiological data related to the incidence and prevalence of osteoporosis. As a result, the sampling framework is designed to include more women than men, and a higher number of older than younger Canadian residents, based on the current knowledge regarding osteoporosis risk factors (4). The study collects detailed demographic information, family history, medical history, medication use, activity, food consumption, health-related quality of life (HRQOL) and lifestyle variables. HRQOL was assessed by means of the Medical Outcomes Trust's 36-item short form health survey (SF-36) (7), and the Health Utilities Index (HUI) $(8,9)$.

Demographic data and responses to the pain variables were obtained from the databases. This paper is based on the prevalence of reported pain over three time periods (usual pain, pain in the past four weeks and pain in the past week). The NPHS used three questions to reference 'usual pain' with no specified time frame. For the purpose of this paper, the NPHS definition will be referred to as 'chronic pain'. CaMos collected responses to the SF-36, which referenced pain in the past four weeks and the HUI, which referenced pain in the week before participation. Both the SF-36 and the HUI would therefore collect both short term or acute pain as well as chronic pain. However, they will be referred to collectively as short term pain and will be referred to individually as 'four-week pain' and 'one-week pain', respectively. Table 1 contains the content and response options for the questions used. Data are presented as frequencies and percentages overall and stratified by age and sex. The study is designed to describe the prevalence of self-reported pain on the basis of question asked, time frame used, age of respondent and sex of respondent. In addition, the overall prevalence estimates of pain reported in the CaMos (four-week pain and one-week pain) have been adjusted, using direct standardization, to the population distribution of the NPHS, thereby removing the effect of sampling method and allowing for assessment of the impact of measurement on overall rates. Direct standardization using the Canadian Census data was repeated and produced the same results (data not included). Bivariate analysis was not performed to assess for statistically significatnt differences in prevalence estimates by age or sex because statistically significant $P$ values would have been generated for even the smallest differences in prevalence, due to large sample sizes.

\section{RESULTS}

The demographic characteristics of the NPHS and CaMos study participants are presented in Table 2. Due to the different sampling frames, CaMos study participants were more likely to be female and older compared with the NPHS participants (Table 2). Table 3 presents unadjusted and adjusted overall prevalence estimates. The CaMos overall unadjusted pain prevalence estimates were higher than the estimates adjusted to the NPHS data. Overall adjusted prevalence of one-week pain was $39 \%$ and four-week pain was $66 \%$. The prevalence of pain interfering with work in the past four weeks was 38\%. Fifteen per cent of respondents reported chronic pain. Tables 4-7 are based on unadjusted CaMos figures.

\section{One-week pain (CaMos - HUI)}

The prevalence and impact of pain in the past week on activities are presented in Table 4. Forty-six per cent of the sample reported pain. Women were more likely to report pain than men $(48.4 \%$ versus $40.5 \%)$. Men were more likely to report 
TABLE 1

Pain questions asked in the National Population and Health Survey (NPHS) and the Canadian Multicentre Osteoporosis Study (CaMos)

\section{NPHS}

1. Are you usually free of pain or discomfort? Yes/No

2. How would you describe the usual intensity of your pain or discomfort? Mild/Moderate/Severe

3. How many activities does your pain or discomfort prevent? None/Few/Some/Most

CaMos - SF-36

1. How much bodily pain have you had during the past four weeks? None/Very mild/Mild/Moderate/Severe/Very severe

2. During the past four weeks, how much did pain interfere with your normal work (including both work outside the home and housework)? Not a bit/A little bit/Moderately/Quite a bit/Extremely

CaMos - HU

1. Are you free of pain and discomfort? (refers to 'over the past week') Yes/No

2. If not, which one of the following best describes your level of pain? Do you have:

a) mild to moderate pain that prevents no activities,

b) moderate pain that prevents a few activities,

c) moderate to severe pain that prevents some activities,

d) severe pain that prevents most activities.

3. Are you free of pain and discomfort? (refers to 'over the past week' and is asked at the end of the questionnaire for a second time) Yes/No

4. If not, which one of the following best describes your usual level of pain?

a) Occasional pain. Discomfort relieved by nonprescription drugs or self-control activity without disruption of normal activities

b) Frequent pain. Discomfort relieved by oral medicines with occasional disruption of normal activities

c) Frequent pain. Frequent disruption of normal activities. Discomfort requires prescription narcotics for relief

d) Severe pain. Pain not relieved by drugs and constantly disrupts normal activities.

Data from references 3 and 4. HUI Health Utilities Index; SF-36 Medical Outcomes Trust 36-item short form health survey

mild to moderate pain preventing no activities ( $49.5 \%$ versus $43.1 \%)$. The degree to which moderate to severe pain prevented some or most activities generally increased with increased age for both sexes.

The prevalence, medication use and disruption of normal activities due to pain in the past week are presented in Table 5 . Forty-eight per cent of the sample reported pain. Women were more likely to report pain than men $(50.7 \%$ versus $41.3 \%)$. Of those who reported pain, approximately two-thirds reported occasional pain that was relieved by nonprescription drug use. Women were somewhat more likely than men to report pain that was not relieved by any drugs (2.6\% versus $1.9 \%)$.

Four-week pain (CaMos - SF-36)

The prevalence and severity of bodily pain in the past four weeks reported in the CaMos survey are presented in Table 6. Sixty-nine per cent of the sample reported pain. Half reported
TABLE 2

Overall prevalence of pain and demographic

characteristics of participants in the 1996-97 National

Population and Health Survey (NPHS) and the Canadian

Multicentre Osteoporosis Study (CaMos)

\begin{tabular}{lcccc}
\hline & \multicolumn{2}{c}{ NPHS } & \multicolumn{2}{c}{ CaMos } \\
Variable & $(\mathbf{n}) \times \mathbf{1 0 0 0}$ & $\mathbf{\%}^{*}$ & $(\mathbf{n}) \times \mathbf{1 0 0 0}$ & $\%$ \\
\hline Age & & & & \\
$25-34$ & 4467 & 19.1 & 400 & 4.2 \\
$35-44$ & 5235 & 22.3 & 499 & 5.3 \\
$45-54$ & 3767 & 16.1 & 1696 & 18.0 \\
$55-64$ & 2555 & 10.9 & 2278 & 24.2 \\
$65-74$ & 2091 & 8.9 & 2938 & 31.2 \\
$75+$ & 1309 & 5.6 & 1612 & 17.1 \\
Sex & & & & \\
$\quad$ Male & 9485 & 48.7 & 2884 & 30.6 \\
Female & 9976 & 51.3 & 6539 & 69.4
\end{tabular}

Living arrangements

$\begin{array}{lcccc}\text { Live alone } & 2949 & 15.2 & 2830 & 30.0 \\ \text { At least one other adult } & 13,556 & 69.7 & 6479 & 68.8 \\ \text { Not alone/no adult } & 1276 & 6.6 & 86 & 0.9 \\ \text { Other/missing } & 1679 & 8.6 & 28 & 0.3\end{array}$

Education

$\begin{array}{lllll}\text { No school/Some secondary } & 4.687 & 24.1 & 3492 & 37.1\end{array}$

$\begin{array}{lllll}\text { Secondary graduate } & 3376 & 17.3 & 1367 & 14.5\end{array}$

$\begin{array}{lllll}\text { Some university } & 940 & 4.8 & 687 & 7.3\end{array}$

$\begin{array}{lllll}\text { Trade school/Other } & 7017 & 36.1 & 2357 & 25.0\end{array}$

post secondary

University degree$$
3289
$$

1519

16.1

Self-reported health status

Poor

512

Fair

Good

Very good

1652

5454

7278

4565

$$
2.6
$$

132

905

1.4

Excellent

28.0

3036

9.6

37.4

3750

32.3

39.8

$23.5 \quad 1590$

16.9

Income quintile

Low

Low middle

701

Middle

1740

3.6

$-^{\dagger} \quad-\dagger$

Upper middle

4856

8.9

25.0

High income

6517

33.5

13.2

Not stated

3075

15.8

$-^{\dagger} \quad-\dagger$

$\begin{array}{lll}\dagger & - \\ - & -\end{array}$

$-^{\dagger} \quad-\dagger$

$-^{\dagger} \quad-{ }^{\dagger}$

Working status

Working

Not working

Other

11783

60.5

4559

48.4

6429

33.0

4600

48.8

1250

6.4

264

2.8

Smoking status

Smoker

Former smoker

5420

Never smoked

6091

27.8

1467

15.6

7880

31.3

3540

37.5

Data from references 3 and 4. *May not add up to $100 \%$ due to rounding and missing or not stated responses; † Data not available. 
TABLE 3

Overall prevalence of chronic pain based on responses to the 1996/97 NPHS and age- and sex-standardized prevalence estimates of short term pain based on the CaMos

\begin{tabular}{|c|c|c|c|}
\hline \multirow[b]{2}{*}{ Reported Pain } & \multicolumn{2}{|c|}{ Prevalence $(\%)$} & \multirow[b]{2}{*}{ Data source } \\
\hline & Unadjusted & Adjusted $^{\dagger}$ & \\
\hline 1-week and impact on activities & 46.0 & 39.0 & CaMos \\
\hline 1-week and impact on medication use & 47.8 & 39.8 & CaMos \\
\hline 4-week & 69.3 & 66.1 & CaMos \\
\hline 4-week and interfered with work & 42.3 & 37.9 & CaMos \\
\hline Chronic & - & 15.1 & NPHS \\
\hline
\end{tabular}

Data from references 3 and $4 .{ }^{\dagger}$ CaMos data, age- and sex-standardized estimates using the NPHS population distribution. CaMos Canadian Multicentre Osteoporosis Study; NPHS National Population and Health Survey

\section{TABLE 4}

Prevalence and impact on activities in the one week before participation in Canadian Multicentre Osteoporosis Study by sex and age group, 1995/96

\begin{tabular}{|c|c|c|c|c|c|c|}
\hline & \multirow[b]{2}{*}{$\begin{array}{c}\text { Sample } \\
\mathrm{n}\end{array}$} & \multirow[b]{2}{*}{$\begin{array}{l}\text { Total with } \\
\text { recent pain } \\
\mathrm{n}(\%)\end{array}$} & \multicolumn{4}{|c|}{ Severity } \\
\hline & & & $\begin{array}{c}\text { Mild to } \\
\text { moderate, } \\
\text { prevents } \\
\text { no activities } \\
\%\end{array}$ & $\begin{array}{c}\text { Moderate, } \\
\text { prevents } \\
\text { a few } \\
\text { activities } \\
\%\end{array}$ & $\begin{array}{c}\text { Moderate } \\
\text { to severe } \\
\text { prevents } \\
\text { activities } \\
\%\end{array}$ & $\begin{array}{c}\text { Severe, } \\
\text { prevents } \\
\text { most } \\
\text { activities } \\
\%\end{array}$ \\
\hline Both sexes & 9421 & $4,334(46.0)$ & 44.8 & 33.9 & 17.3 & 3.9 \\
\hline $25-34$ & 400 & $115(28.8)$ & 53.0 & 34.8 & 9.6 & 2.6 \\
\hline $35-44$ & 499 & $184(36.9)$ & 51.9 & 32.2 & 13.7 & 2.2 \\
\hline $45-54$ & 1696 & $658(38.8)$ & 47.7 & 32.5 & 16.3 & 3.5 \\
\hline $55-64$ & 2278 & $1053(46.2)$ & 46.3 & 33.0 & 18.1 & 2.6 \\
\hline $65-74$ & 2937 & 1465 (49.9) & 44.4 & 33.7 & 16.9 & 5.0 \\
\hline $75+$ & 1611 & 859 (53.3) & 38.9 & 36.8 & 19.6 & 4.7 \\
\hline Women & 6537 & 3165 (48.4) & 43.1 & 35.1 & 17.8 & 4.0 \\
\hline $25-34$ & 200 & $59(29.5)$ & 47.5 & 39.0 & 11.9 & 1.7 \\
\hline $35-44$ & 286 & $103(36.0)$ & 48.5 & 35.0 & 12.6 & 3.9 \\
\hline $45-54$ & 1110 & $454(40.9)$ & 43.6 & 35.9 & 17.2 & 3.3 \\
\hline $55-64$ & 1637 & 779 (47.6) & 45.7 & 34.5 & 17.5 & 2.3 \\
\hline $65-74$ & 2137 & $1114(52.1)$ & 44.2 & 33.9 & 17.2 & 4.7 \\
\hline $75+$ & 1167 & $656(56.2)$ & 36.6 & 37.0 & 21.0 & 5.3 \\
\hline Men & 2884 & $1169(40.5)$ & 49.5 & 30.8 & 15.9 & 3.9 \\
\hline $25-34$ & 200 & $56(28.0)$ & 58.9 & 30.4 & 7.1 & 3.6 \\
\hline $35-44$ & 213 & $81(38.0)$ & 56.3 & 28.8 & 15.0 & 0.0 \\
\hline $45-54$ & 586 & $204(34.8)$ & 56.9 & 25.0 & 14.2 & 3.9 \\
\hline $55-64$ & 641 & $274(42.7)$ & 48.2 & 28.8 & 19.7 & 3.3 \\
\hline $65-74$ & 800 & 351 (43.9) & 44.9 & 33.1 & 16.0 & 6.0 \\
\hline $75+$ & 444 & $203(45.7)$ & 46.5 & 36.1 & 14.9 & 2.5 \\
\hline
\end{tabular}

Data from references 3 and 4. Response to the Health Utilities Index questions "are you free of pain and discomfort?" and "if not, which one of the following best describes your level of pain?" (related to activity restrictions).

very mild or mild pain, while $9.8 \%$ reported severe or very severe pain. Men were more likely to report very mild pain, while women were more likely than men to report moderate to very severe pain. The highest prevalence of very severe pain was reported in women 25 to 34 years of age $(2.3 \%)$. When severe and very severe pain were combined, the prevalence of pain tended to increase with increasing age.

The extent to which bodily pain interfered with normal work in the four weeks before the study is presented in Table 7.
TABLE 5

Prevalence of pain and impact on medication use (\%) in the one week before participation in Canadian Multicentre Osteoporosis Study by sex and age group, 1995/96

\begin{tabular}{|c|c|c|c|c|c|c|}
\hline & \multirow[b]{2}{*}{$\underset{n}{\text { Sample }}$} & \multirow[b]{2}{*}{$\begin{array}{l}\text { Total with } \\
\text { recent pain } \\
\text { n (\%) }\end{array}$} & \multicolumn{4}{|c|}{ Severity } \\
\hline & & & $\begin{array}{l}\text { Occasional } \\
\text { pain, non- } \\
\text { prescription } \\
\text { drugs } \\
\%\end{array}$ & $\begin{array}{c}\text { Frequent } \\
\text { pain, oral } \\
\text { medications } \\
\%\end{array}$ & $\begin{array}{c}\text { Frequent } \\
\text { pain, } \\
\text { prescription } \\
\text { narcotics } \\
\%\end{array}$ & $\begin{array}{c}\text { Severe } \\
\text { pain, not } \\
\text { relieved } \\
\text { by drugs } \\
\%\end{array}$ \\
\hline Both sexes & 9422 & 4505 (47.8) & 63.1 & 28.6 & 5.8 & 2.4 \\
\hline $25-34$ & 400 & $115(28.8)$ & 76.1 & 17.7 & 3.5 & 2.7 \\
\hline $35-44$ & 499 & $184(36.9)$ & 72.7 & 21.3 & 4.4 & 1.6 \\
\hline $45-54$ & 1696 & $691(40.7)$ & 65.7 & 26.8 & 4.5 & 2.9 \\
\hline $55-64$ & 2278 & $1075(47.2)$ & 65.1 & 27.7 & 5.2 & 2.0 \\
\hline $65-74$ & 2938 & $1540(52.4)$ & 62.3 & 28.6 & 6.7 & 2.4 \\
\hline $75+$ & 1611 & 900 (55.9) & 56.6 & 34.2 & 6.6 & 2.7 \\
\hline Women & 6538 & $3315(50.7)$ & 61.5 & 29.9 & 6.0 & 2.6 \\
\hline $25-34$ & 200 & $58(29.0)$ & 73.2 & 19.6 & 1.8 & 5.4 \\
\hline $35-44$ & 286 & $102(35.7)$ & 63.4 & 27.7 & 5.9 & 3.0 \\
\hline $45-54$ & 1110 & $479(43.2)$ & 63.1 & 29.3 & 4.9 & 2.7 \\
\hline $55-64$ & 1637 & $805(49.2)$ & 64.5 & 27.8 & 5.6 & 2.0 \\
\hline $65-74$ & 2138 & $1177(55.1)$ & 62.3 & 28.9 & 6.4 & 2.5 \\
\hline $75+$ & 1167 & $694(59.5)$ & 54.6 & 35.7 & 6.7 & 3.0 \\
\hline Men & 2884 & $1190(41.3)$ & 67.6 & 25.0 & 5.5 & 1.9 \\
\hline $25-34$ & 200 & $57(28.5)$ & 78.9 & 15.8 & 5.3 & 0.0 \\
\hline $35-44$ & 213 & $82(38.5)$ & 84.1 & 13.4 & 2.4 & 0.0 \\
\hline $45-54$ & 586 & $212(36.2)$ & 71.7 & 21.2 & 3.8 & 3.3 \\
\hline $55-64$ & 641 & $270(42.1)$ & 66.7 & 27.4 & 4.1 & 1.9 \\
\hline $65-74$ & 800 & $363(45.4)$ & 62.6 & 27.5 & 7.9 & 2.0 \\
\hline $75+$ & 444 & $206(46.4)$ & 63.4 & 28.8 & 6.3 & 1.5 \\
\hline
\end{tabular}

Data from references 3 and 4. Response to the Health Utilities Index question "are you free of pain and discomfort?" and "if not, which one of the following best describes your level of pain?" (related to medication use and disruption of normal activities).

Forty-two per cent of the sample reported pain interfering with work. Women were more likely than men to report pain interfering with work (45.4\% versus $35.3 \%$ ). Fifty-five per cent who reported that pain interfered with work reported that it interfered a little bit, $28.8 \%$ reported moderate interference and $16.1 \%$ reported that it interfered quite a bit or extremely. Men were more likely than women to report that pain interfered with work a little bit. Younger men were more likely than older men to report that pain interfered extremely with work, while older women were more likely than younger women to report the same.

Chronic pain (NPHS - 1996/97)

The prevalence and severity of chronic pain based on the 1996/97 NPHS data are presented in Table 8. Just over 15\% $(15.1 \%)$ reported chronic pain. Prevalence among women was $16.4 \%$ and prevalence among men was $13.7 \%$. In women, prevalence increased from $9.8 \%$ in the 25 to 34 age group to $28.7 \%$ for ages 75 and older. The prevalence in men for the same age groups increased from $8.1 \%$ to $27.1 \%$. Prevalence increased at a relatively constant rate in women with the largest increase seen in the 45 to 64 year age range, however, in men, the largest increase occurred in ages 75 and older when it increased to $27.1 \%$. 
TABLE 6

Prevalence and severity of pain (\%) in the four weeks before participation in Canadian Multicentre Osteoporosis Study by sex and age group, 1995/96

\begin{tabular}{|c|c|c|c|c|c|c|c|}
\hline & \multirow[b]{2}{*}{$\underset{n}{\text { Sample }}$} & \multirow[b]{2}{*}{$\begin{array}{c}\text { Total } \\
\text { with recent } \\
\text { pain } \\
\mathbf{n}(\%)\end{array}$} & \multicolumn{5}{|c|}{ Severity } \\
\hline & & & $\begin{array}{c}\text { Very } \\
\text { mild } \\
\%\end{array}$ & $\begin{array}{c}\text { Mild } \\
\%\end{array}$ & $\begin{array}{c}\text { Moderate } \\
\%\end{array}$ & $\begin{array}{c}\text { Severe } \\
\%\end{array}$ & $\begin{array}{c}\text { Very } \\
\text { severe } \\
\%\end{array}$ \\
\hline Both sexes & 9413 & $6526(69.3)$ & 36.2 & 24.2 & 29.9 & 8.6 & 1.2 \\
\hline $25-34$ & 400 & $258(64.5)$ & 50.8 & 26.7 & 17.4 & 3.5 & 1.6 \\
\hline $35-44$ & 499 & $321(64.3)$ & 39.6 & 29.6 & 24.9 & 5.0 & 0.9 \\
\hline $45-54$ & 1695 & $1138(67.1)$ & 40.9 & 24.7 & 25.7 & 7.6 & 1.1 \\
\hline $55-64$ & 2278 & $1566(68.7)$ & 36.6 & 24.3 & 29.3 & 8.6 & 1.2 \\
\hline $65-74$ & 2932 & $2073(70.7)$ & 34.6 & 23.3 & 32.1 & 9.0 & 1.0 \\
\hline $75+$ & 1609 & $1170(72.7)$ & 29.7 & 22.8 & 35.1 & 10.9 & 1.5 \\
\hline Women & 6530 & $4680(71.7)$ & 33.5 & 24.0 & 32.0 & 9.3 & 1.3 \\
\hline $25-34$ & 200 & $131(65.5)$ & 46.6 & 24.4 & 22.1 & 4.6 & 2.3 \\
\hline $35-44$ & 286 & $189(66.1)$ & 37.6 & 30.2 & 26.5 & 4.8 & 1.1 \\
\hline $45-54$ & 1109 & 778 (70.2) & 37.3 & 25.7 & 27.5 & 8.4 & 1.2 \\
\hline $55-64$ & 1637 & $1152(70.4)$ & 34.5 & 24.6 & 30.6 & 9.0 & 1.3 \\
\hline $65-74$ & 2133 & 1554 (72.9) & 32.7 & 22.8 & 33.9 & 9.5 & 1.1 \\
\hline $75+$ & 1165 & $876(75.2)$ & 27.3 & 22.4 & 37.0 & 11.6 & 1.7 \\
\hline Men & 2883 & $1846(64.0)$ & 43.0 & 24.6 & 24.7 & 6.8 & 0.9 \\
\hline $25-34$ & 200 & $127(63.5)$ & 55.1 & 29.1 & 12.6 & 2.4 & 0.8 \\
\hline $35-44$ & 213 & $132(62.0)$ & 42.4 & 28.8 & 22.7 & 5.3 & 0.8 \\
\hline $45-54$ & 586 & $360(61.4)$ & 48.6 & 22.5 & 21.9 & 5.8 & 1.1 \\
\hline $55-64$ & 641 & $414(64.6)$ & 42.5 & 23.7 & 25.6 & 7.2 & 1.0 \\
\hline $65-74$ & 799 & $519(65.0)$ & 40.3 & 25.0 & 26.6 & 7.5 & 0.6 \\
\hline $75+$ & 444 & $294(66.2)$ & 36.7 & 24.1 & 29.6 & 8.5 & 1.0 \\
\hline
\end{tabular}

Data from references 3 and 4. Response to the Medical Outcomes Trust's 36-item health survey question "how much bodily pain have you had during the past 4 weeks?"

The impact of chronic pain on activities is presented in Table 9. Of those who reported pain, $25.0 \%$ reported no impact on activities and $17.8 \%$ reported that pain prevented most activities. Men were more likely than women to report no activity limitation $(28.9 \%$ versus $21.9 \%)$, but were also more likely to report that pain prevented most activities (19.7\% versus $16.3 \%)$. Women were more likely than men to report that pain prevented few $(36.0 \%$ versus $31.0 \%)$ or some (25.8\% versus $20.5 \%)$ activities. Activity limitation increased with age for both sexes, but it increased more dramatically for women than men.

\section{Comparison of $1994 / 95$ and $1996 / 97$ NPHS}

Results from the previous (1994-95) NPHS (1) revealed an overall prevalence of chronic pain of $17 \%$, while the current (1996-97) NPHS data revealed a prevalence of $15.1 \%$. Although there has been a reduction in the overall prevalence of chronic pain in Canada over the two-year sampling period between the two NPHS surveys, the distribution of pain severity has not appreciably changed. Women are still more likely to report chronic pain and increasing age is strongly associated with greater prevalence estimates of chronic pain in both sexes.

\section{DISCUSSION}

Pain has varying levels of prevalence in the general population and its epidemiology is not well understood. Estimates of
TABLE 7

Extent to which pain Interfered with normal work (\%) in the four weeks before participation in Canadian Multicentre Osteoporosis Study by sex and age group, $1995 / 96$

\begin{tabular}{|c|c|c|c|c|c|c|}
\hline & \multirow[b]{2}{*}{$\underset{n}{\text { Sample }}$} & \multirow{2}{*}{$\begin{array}{c}\text { Total } \\
\text { reporting } \\
\text { that pain } \\
\text { interfered } \\
n(\%)\end{array}$} & \multicolumn{4}{|c|}{ Severity } \\
\hline & & & $\begin{array}{c}\text { A little } \\
\text { bit } \\
\%\end{array}$ & $\begin{array}{c}\text { Moderately } \\
\%\end{array}$ & $\begin{array}{c}\text { Quite } \\
\text { a bit } \\
\%\end{array}$ & $\begin{array}{c}\text { Extremely } \\
\%\end{array}$ \\
\hline Both sexes & 9413 & 3979 (42.3) & 55.0 & 28.8 & 13.7 & 2.4 \\
\hline $25-34$ & 400 & 137 (34.3) & 72.3 & 18.2 & 7.3 & 2.2 \\
\hline $35-44$ & 499 & $186(37.3)$ & 64.0 & 26.3 & 8.1 & 1.6 \\
\hline $45-54$ & 1695 & $653(38.5)$ & 55.7 & 29.2 & 12.9 & 2.1 \\
\hline $55-64$ & 2278 & 931 (40.9) & 55.0 & 29.0 & 13.3 & 2.7 \\
\hline $65-74$ & 2932 & $1293(44.1)$ & 52.9 & 30.5 & 14.4 & 2.2 \\
\hline $75+$ & 1609 & 779 (48.4) & 52.9 & 28.0 & 16.2 & 3.0 \\
\hline Women & 6530 & $2963(45.4)$ & 53.4 & 29.5 & 14.6 & 2.5 \\
\hline $25-34$ & 200 & $78(39.0)$ & 66.7 & 20.5 & 11.5 & 1.3 \\
\hline $35-44$ & 286 & $120(42.0)$ & 61.7 & 27.5 & 10.0 & 0.8 \\
\hline $45-54$ & 1109 & $464(41.8)$ & 51.1 & 33.2 & 13.8 & 1.9 \\
\hline $55-64$ & 1637 & 713 (43.6) & 54.8 & 28.6 & 13.7 & 2.8 \\
\hline $65-74$ & 2133 & 996 (46.7) & 52.1 & 30.3 & 15.2 & 2.4 \\
\hline $75+$ & 1165 & $592(50.8)$ & 52.0 & 28.0 & 16.6 & 3.4 \\
\hline Men & 2883 & $1016(35.3)$ & 59.9 & 26.8 & 11.1 & 2.2 \\
\hline $25-34$ & 200 & $59(29.5)$ & 79.7 & 15.3 & 1.7 & 3.4 \\
\hline $35-44$ & 213 & $66(31.0)$ & 68.2 & 24.2 & 4.5 & 3.0 \\
\hline $45-54$ & 586 & $189(32.3)$ & 67.2 & 19.6 & 10.6 & 2.6 \\
\hline $55-64$ & 641 & $218(34.0)$ & 55.5 & 30.3 & 11.9 & 2.3 \\
\hline $65-74$ & 799 & $297(37.2)$ & 55.6 & 31.0 & 11.8 & 1.7 \\
\hline $75+$ & 444 & $187(42.1)$ & 55.6 & 27.8 & 15.0 & 1.6 \\
\hline
\end{tabular}

Data from references 3 and 4. Response to the Medical Outcomes Trust's 36-item health survey question "during the past 4 weeks how much did pain interfere with your normal work (including both work outside the home and housework)?"

chronic pain in the general population range from $2 \%$ to $46 \%$ (2). The principle sources of heterogeneity in pain prevalence estimates are in the measurement domain (measurement differences with respect to pain duration and specific question wording) and in the sampling domain (lack of representativeness of the general population) as illustrated by the prevalence estimates reported in the NPHS and the CaMos. Adjustment for sampling bias through direct standardization of the CaMos with the NPHS marginally decreased the heterogeneity between prevalence estimates; however, wide variation in prevalence estimates remained. The remaining variation is largely due to measurement bias (ie, definition used).

International and national studies display similar variations in prevalence estimates. A random sample of patients from general practices in the United Kingdom, reported the prevalence of chronic pain at $46.5 \%$ (2), while a population-based telephone survey in Australia reported a prevalence of $17 \%$ in men and 20\% in women (10). The prevalence of chronic pain in an Israeli population was estimated at 10\% (11), while Croft et al (12) found a prevalence of $11 \%$ in a postal survey of adults in England. Prevalence estimates in Canadian studies ranged from $11 \%$ to $44 \%(13,14)$. 
TABLE 8

Prevalence and severity of chronic pain in Canada by sex and age group based on the National Population and Health Survey 1996/97

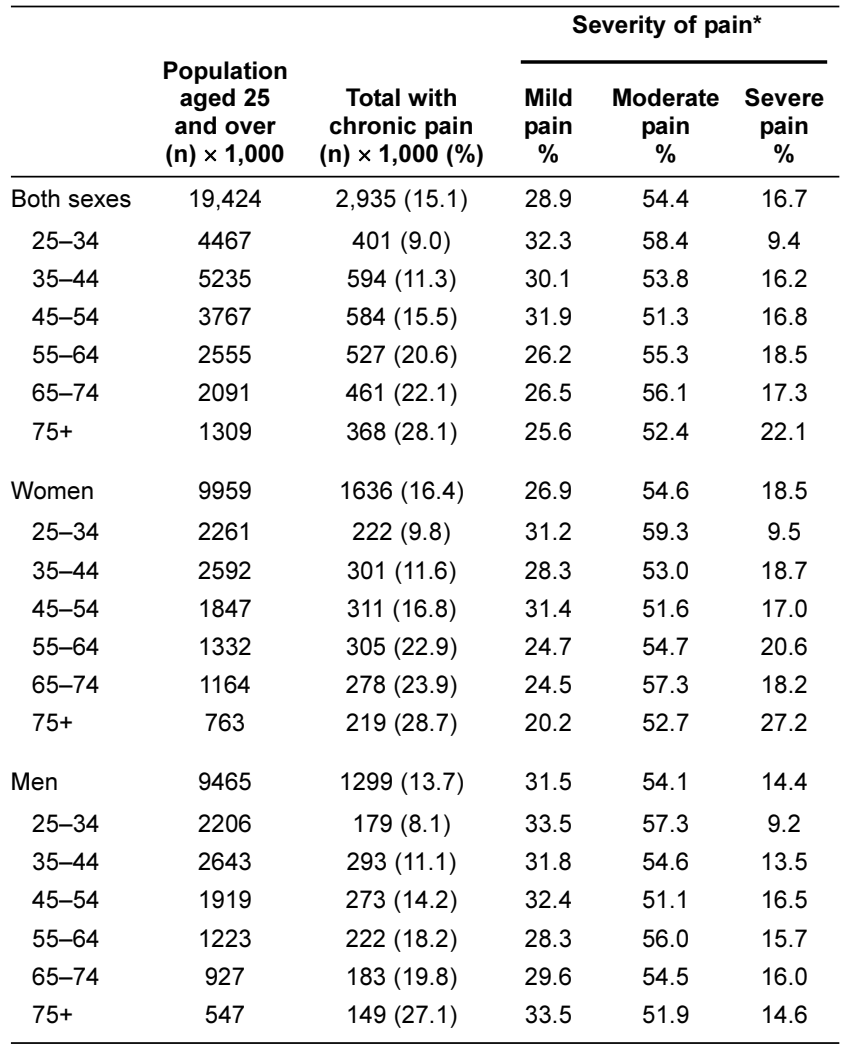

Data from references 3 and 4 . Responses to the question on the severity of pain were not provided by 36,490 individuals

These studies, drawn from the chronic pain literature, illustrate that the primary factors influencing the reported level of chronic pain in the general population are related to the selection of the subsample and the definition used. Definitions in the literature ranged from general definitions, such as, 'usually have pain or discomfort', to more specific definitions, such as pain defined by a validated pain questionnaire. In Canadian studies, the highest levels of pain reported used either a validated questionnaire $(2,15)$, or were based on a pain definition of a relatively lengthy duration (13), as illustrated by the studies by Birse (13) and Moulin (16). Both cross sectional telephone surveys defined pain as lasting at least six months. In 1998, Birse reported a chronic pain prevalence of $44 \%$ (men respondents $=34.5 \%$, women respondents $=65.5 \%$ ) in the general population in Edmonton (13). In 2002 Moulin reported a prevalence of chronic pain of $29 \%$ in a stratified random sample of Canadians (16), however, the estimate may have been affected by sampling bias given the response rate of $19.1 \%$. The lowest level of reported pain (11\%) was reported by Crook in 1984 (14). A two-part definition of pain was used to capture persistent pain ("Do you usually or always have pain?"; "Has this pain been present in the past two weeks?"). Those not reporting pain in the past two weeks were excluded from the persistent pain sample. Finally, a change in awareness and attitude towards pain over the past 18 years may have also had an impact on the disparity in prevalence estimates in the abovementioned studies.
TABLE 9

Prevalence and impact on activities of chronic pain in Canada by sex and age group based on the National Population and Health Survey 1996/97

\begin{tabular}{|c|c|c|c|c|c|c|}
\hline & \multirow[b]{2}{*}{$\begin{array}{l}\text { Population } \\
\text { aged } 25 \\
\text { and over } \\
(\mathrm{n}) \times 1000\end{array}$} & \multirow[b]{2}{*}{$\begin{array}{c}\text { Total with } \\
\text { chronic pain } \\
\text { (n) } \times 1000(\%)\end{array}$} & \multicolumn{4}{|c|}{ Degree of activity limitation* } \\
\hline & & & $\begin{array}{c}\text { Prevents } \\
\text { no } \\
\text { activities } \\
\%\end{array}$ & $\begin{array}{c}\text { Prevents } \\
\text { few } \\
\text { activities } \\
\%\end{array}$ & $\begin{array}{l}\text { Prevents } \\
\text { some } \\
\text { activities } \\
\%\end{array}$ & $\begin{array}{c}\text { Prevents } \\
\text { most } \\
\text { activities } \\
\%\end{array}$ \\
\hline Both sexes & 19,432 & $2943(15.1)$ & 25 & 33.8 & 23.5 & 17.8 \\
\hline $25-34$ & 4467 & $401(9.0)$ & 29.8 & 38.8 & 18.5 & 12.9 \\
\hline $35-44$ & 5236 & $595(11.4)$ & 26.6 & 33.8 & 23.5 & 16.2 \\
\hline $45-54$ & 3767 & $584(15.5)$ & 31.1 & 28.7 & 21.3 & 19 \\
\hline $55-64$ & 2556 & $528(20.7)$ & 23.2 & 33.4 & 25 & 18.3 \\
\hline $65-74$ & 2092 & $462(22.1)$ & 21.8 & 36.9 & 25.8 & 15.5 \\
\hline $75+$ & 1314 & $372(28.3)$ & 14 & 32.9 & 27.3 & 25.8 \\
\hline Women & 9964 & $1641(16.5)$ & 21.9 & 36 & 25.8 & 16.3 \\
\hline $25-34$ & 2261 & $222(9.8)$ & 26.2 & 42.7 & 21 & 10.1 \\
\hline $35-44$ & 2592 & $302(11.6)$ & 21 & 40.6 & 24.9 & 13.5 \\
\hline $45-54$ & 1847 & $311(16.8)$ & 25.4 & 32.1 & 22.8 & 19.6 \\
\hline $55-64$ & 1332 & 305 (22.9) & 20.1 & 36.3 & 28.7 & 14.9 \\
\hline $65-74$ & 1164 & 278 (23.9) & 23.7 & 34.6 & 27.2 & 14.5 \\
\hline $75+$ & 767 & $223(29.1)$ & 14 & 29.5 & 30.5 & 25.9 \\
\hline Men & 9468 & 1301 (13.7) & 28.9 & 31 & 20.5 & 19.7 \\
\hline $25-34$ & 2206 & $179(8.1)$ & 34.2 & 34 & 15.5 & 16.3 \\
\hline $35-44$ & 2644 & $293(11.1)$ & 32.3 & 26.7 & 22 & 19 \\
\hline $45-54$ & 1920 & $273(14.2)$ & 37.6 & 24.7 & 19.5 & 18.2 \\
\hline $55-64$ & 1224 & $223(18.2)$ & 27.6 & 29.4 & 19.8 & 23.1 \\
\hline $65-74$ & 927 & $184(19.8)$ & 18.9 & 40.3 & 23.6 & 17.1 \\
\hline $75+$ & 547 & $149(27.3)$ & 13.8 & 38 & 22.4 & 25.7 \\
\hline
\end{tabular}

Data from references 3 and 4 . Responses to the question on activity limitation were not provided by 28,889 individuals

Contrary to the stated literature, we found that use of a validated question and a relatively lengthy duration resulted in the lowest levels of reported pain (NPHS). The high prevalence estimates of short term pain were based on standardized estimates of HRQOL that included questions regarding pain and were targeted towards individuals more likely to experience higher levels of pain, with greater representation of older age strata (CaMos). Yet, standardization of the estimates only resulted in slight decreases in the overall estimate of pain, providing further evidence for the importance of measurement (ie, definition) in comparing prevalence estimates of pain.

The strengths of the CaMos and the NPHS relate to the fact that they are both large, randomly conducted and rigorously sampled, population-based Canadian studies with adequate response rates, making them likely to be representative of the Canadian noninstitutionalized population. A comparison of the results of each of the different questions provides valuable insights not only into the prevalence of self-reported pain in the Canadian population, but also the significant impact of question asked, the time frame used, and the age and sex of the respondent on the responses obtained.

In terms of the prevalence of pain in Canada, the results of the SF-36 and HUI are more similar to one another than they are to the NPHS. The NPHS consistently reports lower percentages of people affected with chronic pain, probably 
because the questions designed to measure the prevalence of pain were quite different between the two studies. The SF-36 asked about the prevalence of any bodily pain within the past four weeks, while the HUI asked if the subject was free of pain and discomfort in the past week. Both the SF-36 and HUI will likely capture those with short term acute pain (eg, headaches, migraines, dental pain or menstrual cramps), as well as chronic pain. The NPHS, in contrast, asked the subjects if they were usually free of pain and discomfort, with no time frame attached. The NPHS question, therefore, is more likely to identify those with chronic and long lasting pain complaints, rather than minor or transient bodily pain.

There are a number of limitations with the NPHS and CaMos data. First, the analyses do not cover residents of institutions, and thereby, likely exclude a substantial number of people who have pain. Second, the data are self-reported, and have not been independently validated. Third, like all other available prevalence estimates, these data are cross-sectional, which limits the conclusions that can be drawn.

However, this study yields useful information about the selfreported responses to a variety of questions assessing pain in the general population. It is particularly useful in illustrating the impact of the question asked, the age of the respondent and the sex of the respondent on the estimates obtained. These results highlight the need for extremely careful definitions of the variable of interest and the time frame selected, as these have a significant impact on the responses elicited. In addition, any study attempting to estimate the prevalence of pain in the population must ensure representativeness of the general population through both adequate sampling and satisfactory response rates.

Responses to the different questions likely represent different categories of short term and chronic pain, which in turn may have different epidemiological risk factors and profiles. Longitudinal studies of the epidemiology, predictors, and natural history of chronic pain are urgently needed in the Canadian

\section{REFERENCES}

1. Millar WJ. Chronic pain. Health Rep 1996;7:47-53.

2. Elliott AM, Smith BH, Penny KI, Smith WC, Chambers WA.

The epidemiology of chronic pain in the community. Lancet 1999;354:1248-52.

3. Statistics Canada. National Population Health Survey Overview 1996-97. Ottawa: Statistics Canada, 1998:82-567.

4. Kreiger N, Tenenhouse A, Joseph L, et al. The Canadian Multicentre Osteoporosis Study (CaMos): Background, rationale, methods. Can J Aging 1999;18:376-87.

5. Tambay J-L, Catlin G. Sample design of the National Population Health Survey. Health Rep 1995;7:29-38.

6. Hopman WM, Towheed TE, Anastassiades T. Canadian normative data for the SF-36 health survey. CMAJ 2000;163:265-71.

7. Ware JE. SF-36 Health Survey Manual and Interpretation Guide. Boston: The Health Institute, New England Medical Centre, 1993.

8. Torrance GW, Furlong WJ, Feeny DH, Boyle MH. Multiattribute preference functions: Health utilities index. Pharmacoeconomics 1995; 7:503-20.

9. Feeny DH, Furlong WJ, Torrance GW, et al. Multiattribute and single attribute utility functions for the Health Utilities Index Mark 3 system. Med Care 2002;40:113-28.

10. Blyth FM, March LM, Brnabic AJ, Jorm LR, Williamson M, Cousins MJ. Chronic pain in Australia: A prevalence study. Pain 2001;89:127-34.

11. Buskila D, Abramov G, Biton A, Neumann L. The prevalence of population. Such studies may be useful in identifying those whose acute pain syndromes are more likely to become chronic and persistent (17-19). Future research with the CaMos and NPHS survey data will be directed at identifying the correlates of those reporting chronic pain in terms of demographic variables, and the concomitant presence of other diseases and chronic conditions, as well as assessing long term changes in the population.

THE CANADIAN MULTICENTRE OSTEOPOROSIS STUDY RESEARCH GROUP: Alan Tenenhouse (principal investigator), Suzette Poliquin (national coordinator), Suzanne Godmaire (administrative assistant), McGill University, Montreal General Hospital, Montreal, Quebec (coordinating centre); Lawrence Joseph (study statistician), Claudie Berger (statistician), McGill University, Montreal General Hospital, Montreal, Quebec (methods centre); Carol Joyce (centre director), Minnie Parsons (centre coordinator), Memorial University, St John's, Newfoundland; Roger Rittmaster (centre co-director), Susan Kirkland (centre co-director and epidemiologist), Barbara Stanfield (centre coordinator), Dalhousie University, Halifax, Nova Scotia; Jacques P Brown (centre director), and Nathalie Migneault-Roy and Evelyne Lejeune (centre coordinators), Laval University, Quebec, Quebec; Tassos Anastassiades (centre director), and Pamela Hartman and Barbara Matthews (centre coordinators), Queen's University, Kingston, Ontario; Nancy Kreiger (study epidemiologist), Timothy M Murray (centre director), Barbara Gardner-Bray (centre coordinator), University Toronto, Toronto, Ontario; Jonathan D Adachi (centre director), Laura Pickard (centre coordinator), McMaster University, Hamilton, Ontario; Wojciech P Olszynski (centre director), and Pat Krutzen and Jola Kedra (centre coordinators), University of Saskatchewan, Saskatoon, Saskatchewan; David A. Hanley (centre director), Jane Allan (centre coordinator), University of Calgary, Calgary, Alberta; Stuart Jackson (medical physicist), Loralee Robertson (research assistant), University of Alberta, Edmonton, Alberta; Jerilynn C Prior (centre director), Brian Lentle (radiology study consultant), Yvette Vigna (centre coordinator), University British Columbia, Vancouver, British Columbia.

pain complaints in a general population in Israel and its implications for utilization of health services. J Rheumatol 2000;27:1521-5.

12. Croft P, Rigby AS, Boswell R, Schollum J, Silman A. The prevalence of chronic widespread pain in the general population. J Rheumatol 1993;20:710-3.

13. Birse TM, Lander J. Prevalence of chronic pain. Can J Public Health 1998;89:129-31.

14. Crook J, Rideout E, Browne G. The prevalence of pain complaints in a general population. Pain 1984;18:299-314.

15. Elliott AM, Smith BH, Smith WC, Chambers WA. Changes in chronic pain severity over time: The Chronic Pain Grade as a valid measure. Pain 2000;88:303-8.

16. Moulin DE, Clark AJ, Speechley M, Morley-Forster PK. Chronic pain in Canada - Prevalence, treatment, impact and the role of opioid analgesia. Pain Res Manag 2002;7:179-84.

17. Von Korff M. Epidemiological Methods. In: Crombie IK, Croft P, Linton SJ, LeResche L, Von Korff M, eds. Epidemiology of Pain. Seattle: IASP Press, 1999:7-16.

18. McBeth J, Macfarlane GJ, Benjamin S, Silman AJ. Features of somatization predict the onset of chronic widespread pain: Results of a large population-based study. Arthritis Rheum 2001;44:940-6.

19. Coste J, Delecoeuillerie G, Cohen dL, Le Parc JM, Paolaggi JB. Clinical course and prognostic factors in acute low back pain: An inception cohort study in primary care practice. BMJ 1994;308:577-80. 


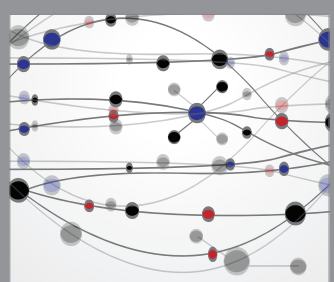

The Scientific World Journal
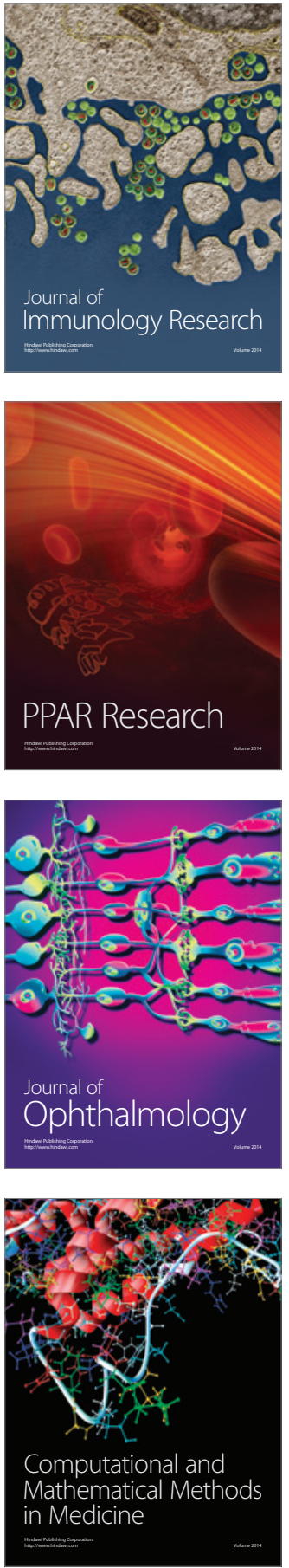

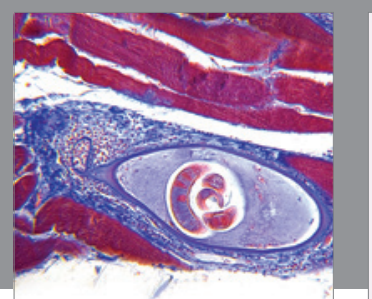

Gastroenterology Research and Practice

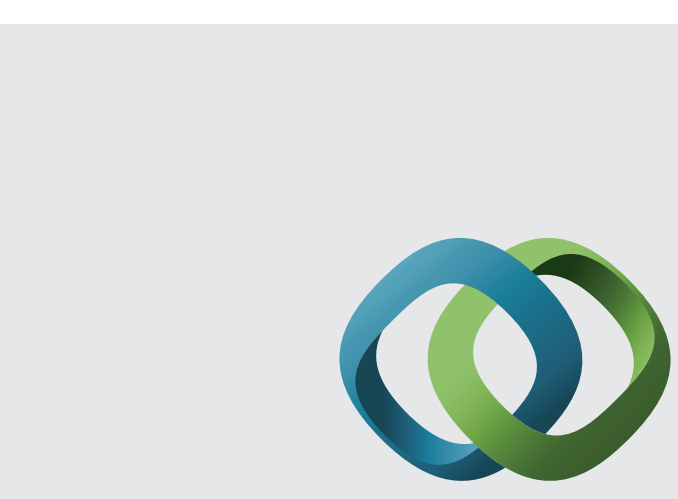

\section{Hindawi}

Submit your manuscripts at

http://www.hindawi.com
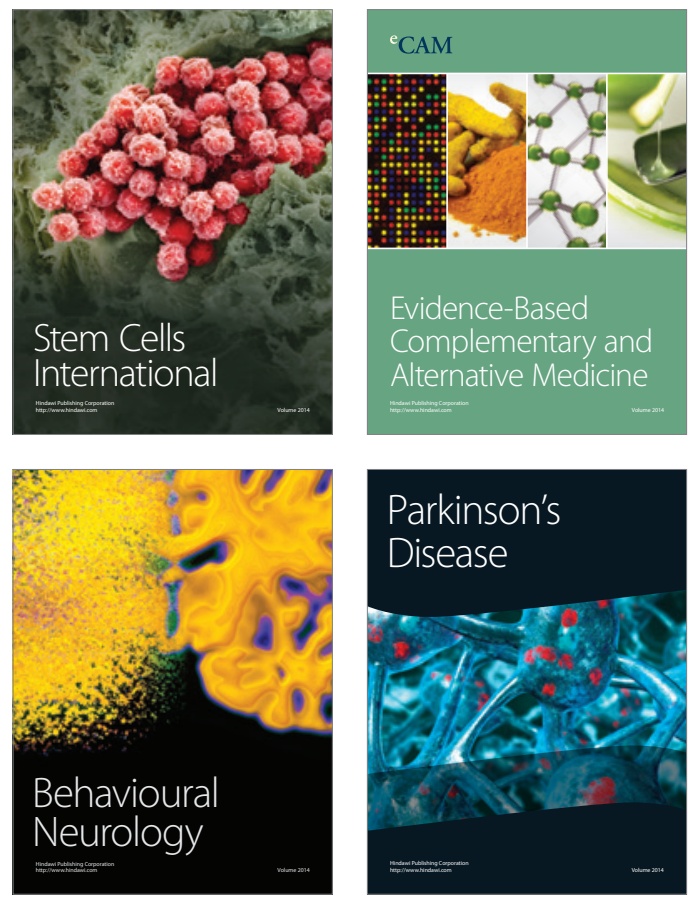
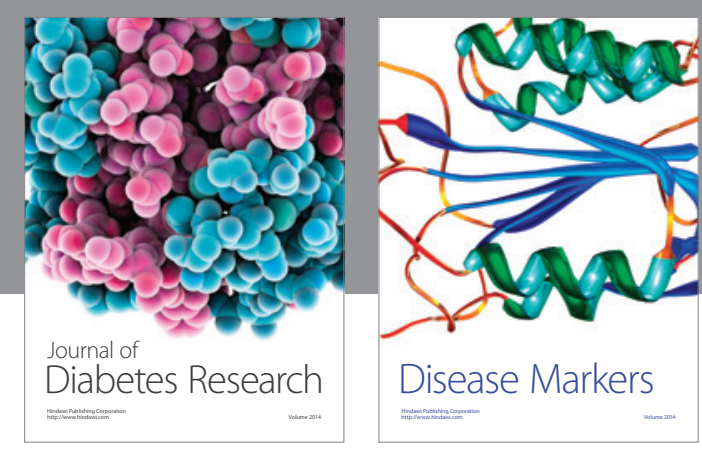

Disease Markers
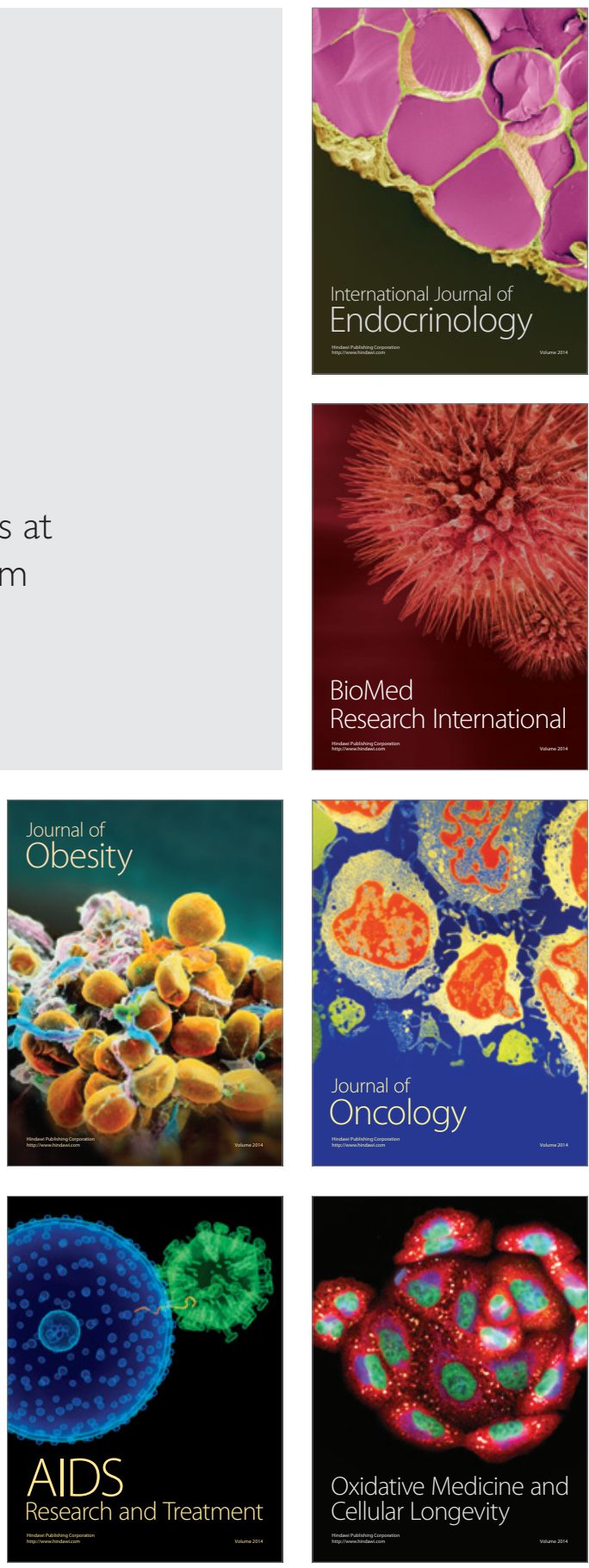